\title{
Crescimento e desenvolvimento de língua-de-vaca
}

Wilian Jochem ${ }^{1}$, Regina Pasinatto Visentin ${ }^{1}$, Beatriz Nogatz ${ }^{1}$, Gabriel Dalla Costa ${ }^{1}$, Jaqueline Schmitt ${ }^{2}$, Antonio Mendes de Oliveira Neto $^{3}$, Naiara Guerra ${ }^{1}$

${ }^{1}$ Universidade Federal de Santa Catarina, Campus de Curitibanos - UFSC. ${ }^{2}$ Universidade Federal de Pelotas - UFPEL.

${ }^{3}$ Universidade do Estado de Santa Catarina - CAV/UDESC. E-mail: naiaraguerra.ng@gmail.com

\section{Resumo}

A língua-de-vaca é uma planta daninha perene, que infesta principalmente pastagens, lavouras anuais e perenes na região Sul do Brasil. Por ser uma planta perene, o controle se torna mais difícil devido ao rebrote. O trabalho teve como objetivo acompanhar a fenologia e avaliar as características de crescimento e desenvolvimento de plantas de língua-de-vaca em ambiente não competitivo. O experimento foi conduzido em casa de vegetação, após as sementes terem germinado em câmara BOD, as plântulas foram transplantadas para vasos preenchidos com Cambissolo Háplico. Foram realizadas análises destrutivas aos 0, 33, 94, 124, 156, 186 e 215 dias após o transplantio (DAT). As plantas foram coletadas separando a parte aérea do sistema radicular e da inflorescência, cada parte da planta foi levada à estufa de secagem por circulação forçada de ar para posterior determinação da massa seca. Observou-se que as plantas de línguade-vaca apresentam crescimento inicial bastante lento. A distribuição da massa seca total foi de $56,8 \%$ do total acumulado no sistema radicular, seguido pela inflorescência (31,6\%) e parte aérea (11,6\%). 0 número médio de sementes produzidas foi de 3.406 ( \pm 389 ) por plantas.

Palavras-chave: Rumex obtusifolius; massa seca; fenologia; Polygonaceae.

\section{Growth and development of broad leaved dock}

\begin{abstract}
Broad-leaved dock is a perennial weed, which infests mainly pastures, annual crops and perennials in the Southern of Brazil. Because it is a perennial plant, control becomes more difficult due to regrowth. The objective of this study was to evaluate the growth and development characteristics of cow-tongue plants in a non-competitive environment. The objective of this work was to monitor phenology and to evaluate the growth and development characteristics of broad-leaved dock plants in the non-competitive environment. The experiment was conducted in a greenhouse, after the seeds germinated in the BOD chamber, the seedlings were transplanted to pots filled with Cambisol Haplic. Destructive analyzes were performed at 0 , 33, 94, 124, 156, 186 and 215 days after transplanting (DAT). The plants were collected separating the aerial part of the root system and the inflorescence, each part of the plant was taken to the drying oven by forced circulation of air for later determination of the dry mass. It was observed that the broad-leaved dock plants present initial growth rather slow. The total dry mass distribution was $56.8 \%$ of the total accumulated in the root system, followed by inflorescence $(31.6 \%)$ and shoot $(11.6 \%)$. The average number of seeds produced was 3,406 ( \pm 389 ) per plant.
\end{abstract}

Keywords: Rumex obtusifolius; dry matter; phenology; Polygonaceae.

\section{Introdução}

A Rumex obtusifolius, popularmente conhecida como língua-de-vaca, é uma planta daninha perene pertencente à família Polygonaceae, nativa do Brasil e Europa. Está distribuída em altitudes que variam desde o nível do mar até 1500 m (ZALLER, 2004), no Brasil é encontrada nos estados do Rio Grande do Sul, Santa Catarina e Paraná (LORENZI, 2000). 
Essa espécie apresenta grande plasticidade fenotípica, podendo chegar a 1,5 m de altura, suas raízes alcançar até $40 \mathrm{~mm}$ de espessura (ZALLER, 2004). A reprodução ocorre por meio de sementes e rizomas (LORENZI, 2014), sendo que as sementes apresentam dormência, que é perdida gradualmente após o armazenamento, a temperatura ótima para a germinação está entre 20 e $25^{\circ} \mathrm{C}$, na presença ou ausência de luz, a emergência ocorre somente em profundidades inferiores a $8 \mathrm{~cm}$ (BENVENUTI et al., 2001).

Infesta pastagens, lavouras anuais e perenes e terrenos baldios (LORENZI, 2000; ALSHALLASH, 2018), é indicadora de alta concentração de nitrogênio no solo (ZALLER, 2004). A $R$. obtusifolius apresenta elevado potencial competitivo devido sua capacidade de florescer duas vezes por ano, produzir grande número de sementes, que permanecem viáveis no banco de sementes do solo por pelo menos dez anos e que podem germinar em diferentes condições climáticas. Além disso, a espécie apresenta considerável capacidade de rebrotar após o corte de sua parte aérea (CAVERS; HARPER, 1964; ZALLER, 2004).

Além do potencial competitivo, esta espécie possui efeito alelopático, Zaller (2006) verificou inibição da germinação de cinco espécies de gramíneas após as sementes serem colocadas para embeber em extrato aquoso de folhas de $R$. obtusifolius. Segundo Harshaw et al. (2010) esta espécie apresenta propriedades antioxidante e bactericida. A língua-de-vaca também pode ser fonte de inoculo de doenças e pragas de plantas cultivadas, Moccellin et al. (2018) verificaram em plantas desta espécie coletadas em Jaguarão-RS, a presença de Alternaria alternata, agente causal da manchade-alternaria, um importante patógeno que pode afetar diversas lavouras. Ainda é hospedeira do inseto sugador Eurhizococus brasiliensis (pérolada-terra) que ataca videiras e outas espécies cultivadas (MOREIRA, 2011).

Apesar da frequente ocorrência desta espécie no Sul do Brasil, são poucas as pesquisas referentes a mesma, principalmente aquelas que visem conhecer melhor a ecologia da espécie para se determinar o melhor método e momento de controle. Estudos sobre o crescimento e desenvolvimento das plantas daninhas fornecem informações sobre os diferentes estádios fenológicos e padrões de crescimento vegetal (PATTERSON, 1984; CARVALHO et al., 2008).
Esses estudos permitem a análise do comportamento das plantas perante os fatores ecológicos, bem como sua ação sobre o ambiente, principalmente quanto a sua interferência sobre outras plantas, o que pode contribuir para o desenvolvimento de sistemas de manejo integrado de plantas daninhas (BIANCO et al., 2014; 2015).

Desta forma, o presente trabalho teve como objetivo acompanhar a fenologia e avaliar as características de crescimento e desenvolvimento de plantas de língua-de-vaca em ambiente não competitivo.

\section{Material e Métodos}

$O$ experimento foi conduzido em casa de vegetação entre os meses de abril a dezembro de 2017, na área de pesquisa do Centro de Ciências Rurais da Universidade Federal de Santa Catarina (UFSC) - Campus de Curitibanos, que está localizada na Rodovia Ulysses Gaboardi, km 3, Curitibanos -SC, a $27^{\circ} 17^{\prime} 03^{\prime \prime} \mathrm{S}$ de latitude e a $50^{\circ} 32^{\prime} 05^{\prime \prime} \mathrm{O}$ de longitude com altitude de 1096 $\mathrm{m}$.

Sementes de Rumex obtusifolius foram coletadas a campo e antes de serem semeadas passaram pelo método de escarificação física, por meio de lixa de parede número 2, para a quebra da dormência. Após a quebra de dormência estas foram semeadas em caixas tipo gerbox, com duas folhas de papel germiteste previamente umedecidas, as caixas então foram dispostas em câmara tipo $B O D$ a $20^{\circ} \mathrm{C}$, durante o período de germinação. Após este período, que ocorreu sete dias após a semeadura, foi realizado o transplantio de uma plântula contendo duas folhas cotiledonares por unidade experimental. A unidade experimental foi representada por vasos com capacidade de 11 litros, preenchidos com solo classificado como Cambissolo Háplico. Estes vasos permaneceram em bancada na casa de vegetação durante todo o período de condução e foram irrigados conforme a necessidade.

O delineamento experimental adotado foi $o$ de blocos casualizados com sete tratamentos e quatro repetições. Os tratamentos representaram as diferentes épocas de coleta das plantas para a realização da análise destrutiva, sendo estas 0, 33, 94, 124, 156, 186 e 215 dias após o transplantio (DAT).

Para a análise destrutiva as plantas foram coletadas separando a parte aérea do sistema radicular e da inflorescência, cada parte da planta foi acondicionada em sacos de papel e levada à 
estufa de circulação forçada de ar a $65^{\circ} \mathrm{C}$ até atingirem massa constante, para posterior determinação da massa seca. Na última coleta (215 DAT) foi realizada a contagem das sementes presentes em cada planta.

Os dados obtidos foram submetidos ao teste $F$ na análise de variância $(p<0,05)$, análise descritiva e a análise de regressão não linear $(p<0,05)$, com 0 auxílio dos programas estatísticos Sisvar e Sigmaplot.

Além das análises para determinar o acúmulo de massa seca das plantas de $R$. obstusifolius também buscou-se estabelecer uma escala fenológica para essa espécie, para isso utilizou-se a escala BBCH (Biologische
Bundesanstal, Bundessorteatenamt na Chemical Industry) (HESS et al., 1997). Para a determinação de cada fase levou-se em consideração o momento em que $50 \%+1$ das plantas apresentavam a característica pré-estabelecida.

\section{Resultados e Discussão}

O ciclo das plantas de Rumex obtusifolius foi de 215 dias, sendo que desses, 164 foram de ciclo vegetativo e 51 de ciclo reprodutivo. 0 crescimento da parte aérea ocorreu de forma lenta, onde aos 90 DAT apresentava somente 9 folhas. A emissão da inflorescência passou a ser visível a partir de 172 DAT (Tabela 1).

Tabela 1. Estádio fenológico, escala BBCH, data e dias após o transplantio (DAT) e descritor morfológico de plantas de Rumex obtusifolius. Curitibanos, SC, 2017.

\begin{tabular}{cccc}
\hline Data & DAT & Descritor morfológico & Escala BBCH* \\
\hline $28 / 04$ & 0 & Transplantio -2 folhas & 12 \\
$02 / 05$ & 4 & 2 folhas & 12 \\
$11 / 05$ & 13 & 3 folhas & 13 \\
$21 / 05$ & 23 & 4 folhas & 14 \\
$04 / 07$ & 67 & 7 folhas & 17 \\
$27 / 07$ & 90 & 9 folhas & 19 \\
$09 / 08$ & 103 & 10 folhas & 110 \\
$18 / 09$ & 112 & 11 folhas & 111 \\
$25 / 08$ & 119 & 13 folhas & 113 \\
$30 / 08$ & 124 & 15 folhas & 115 \\
$15 / 09$ & 139 & 19 folhas & 119 \\
$02 / 10$ & 156 & 19 folhas & 119 \\
$10 / 10$ & 164 & 19 folhas & 119 \\
$18 / 10$ & 172 & Emissão de inflorescência & 60 \\
$23 / 10$ & 177 & Florescimento & 65 \\
$01 / 11$ & 186 & Início da maturação dos frutos & 81 \\
$30 / 11$ & 215 & Maturação completa & 89 \\
$05 / 12$ & 220 & Corte da parte aérea remanescente & - \\
$15 / 12$ & 230 & Início do rebrote & 09 \\
\hline
\end{tabular}

* Biologische Bundesanstal, Bundessorteatenamt na Chemical Industry.

Na Tabela 2 estão apresentados os resultados da análise estatística descritiva (valor mínimo, máximo, média, desvio padrão e coeficiente de variação) para o acúmulo de massa seca total, de parte aérea, raiz e inflorescência de plantas de língua-de-vaca. 
Tabela 2. Resultados da estatística descritiva referente ao acúmulo de massa seca total, de parte aérea, raiz e inflorescência de plantas de Rumex obtusifolius. Curitibanos, SC, 2017.

\begin{tabular}{|c|c|c|c|c|c|}
\hline \multicolumn{6}{|c|}{ Massa Seca Total } \\
\hline $\begin{array}{c}\text { Data de coleta } \\
\text { (DAT) }\end{array}$ & Mínimo & Máximo & Média & Desvio Padrão & $\begin{array}{l}\text { Coeficiente de } \\
\text { Variação (\%) }\end{array}$ \\
\hline 33 & 0,02 & 0,03 & 0,02 & 0,05 & 15,98 \\
\hline 94 & 0,11 & 0,25 & 0,19 & 0,06 & 32,93 \\
\hline 124 & 3,57 & 6,39 & 4,83 & 1,39 & 28,90 \\
\hline 156 & 13,16 & 21,81 & 17,61 & 3,90 & 22,15 \\
\hline 186 & 36,09 & 53,21 & 44,93 & 7,83 & 17,44 \\
\hline 215 & 65,16 & 86,78 & 71,63 & 10,30 & 14,42 \\
\hline \multicolumn{6}{|c|}{ Massa Seca da Parte Aérea } \\
\hline $\begin{array}{c}\text { Data de coleta } \\
\text { (DAT) }\end{array}$ & Mínimo & Máximo & Média & Desvio Padrão & $\begin{array}{c}\text { Coeficiente de } \\
\text { Variação (\%) }\end{array}$ \\
\hline 33 & 0,001 & 0,002 & 0,012 & 0,00 & 35,45 \\
\hline 94 & 0,026 & 0,057 & 0,042 & 0,01 & 34,65 \\
\hline 124 & 2,00 & 3,72 & 2,90 & 0,91 & 31,31 \\
\hline 156 & 3,75 & 9,45 & 7,01 & 2,78 & 39,70 \\
\hline 186 & 4,57 & 10,03 & 7,41 & 2,23 & 30,12 \\
\hline 215 & 7,46 & 11,29 & 8,70 & 1,75 & 20,12 \\
\hline \multicolumn{6}{|c|}{ Massa Seca da Raiz } \\
\hline $\begin{array}{c}\text { Data de coleta } \\
\text { (DAT) }\end{array}$ & Mínimo & Máximo & Média & Desvio Padrão & $\begin{array}{c}\text { Coeficiente de } \\
\text { Variação (\%) }\end{array}$ \\
\hline 33 & 0,021 & 0,032 & 0,027 & 0,00 & 17,17 \\
\hline 94 & 0,081 & 0,199 & 0,144 & 0,49 & 33,98 \\
\hline 124 & 1,49 & 2,73 & 1,92 & 0,56 & 29,54 \\
\hline 156 & 9,41 & 12,62 & 10,60 & 1,39 & 13,16 \\
\hline 186 & 28,33 & 43,37 & 35,01 & 7,44 & 21,26 \\
\hline 215 & 34,79 & 52,56 & 40,39 & 8,18 & 20,26 \\
\hline \multicolumn{6}{|c|}{ Massa Seca da Inflorescência } \\
\hline $\begin{array}{c}\text { Data de coleta } \\
\text { (DAT) }\end{array}$ & Mínimo & Máximo & Média & Desvio Padrão & $\begin{array}{c}\text { Coeficiente de } \\
\text { Variação (\%) }\end{array}$ \\
\hline 33 & 0 & 0 & 0 & 0 & 0 \\
\hline 94 & 0 & 0 & 0 & 0 & 0 \\
\hline 124 & 0 & 0 & 0 & 0 & 0 \\
\hline 156 & 0 & 0 & 0 & 0 & 0 \\
\hline 186 & 2,35 & 2,62 & 2,49 & 0,11 & 4,58 \\
\hline 215 & 19,75 & 25,97 & 22,31 & 2,69 & 12,07 \\
\hline
\end{tabular}

O acúmulo total de massa seca das plantas de $R$. obstusifolius em ambiente não competitivo foi de $71,63 \mathrm{~g}^{\text {planta }}{ }^{-1}$. As plantas apresentaram crescimento inicial lento até os 120 DAT, com acúmulo inferior a $2,25 \mathrm{~g}$, o que representa apenas $3 \%$ do total de massa seca acumulada (Figura 1). Esses resultados corroboram com o relato de Zaller (2004) que salienta que esta espécie apresenta baixa habilidade competitiva no início de seu ciclo vegetativo. 
Figura 1. Massa seca total (MS Total), da parte aérea (MS parte aérea), da raiz e inflorescência (MS inflorescência) das plantas de Rumex obtusifolius ao longo de seu ciclo de desenvolvimento. Curitibanos, SC, 2017.

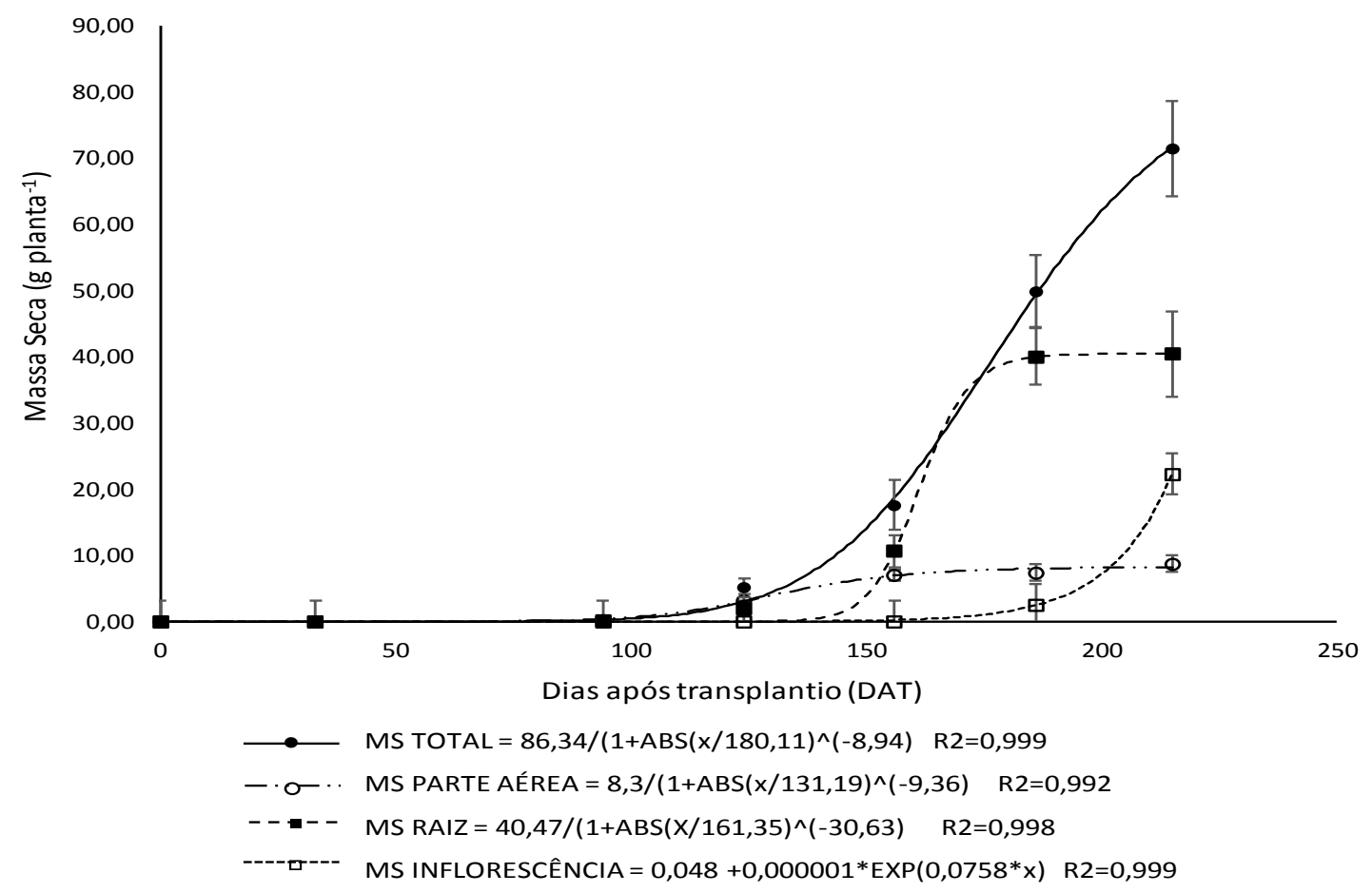

Dos 120 até os 177 DAT o crescimento foi acelerado, saindo de $2,25 \mathrm{~g}$ ( $3 \%$ do total de massa seca acumulada no final do ciclo) para $39,82 \mathrm{~g}$ ( $55 \%$ do total de massa seca acumulada no final do ciclo) em um período de 57 dias. No entanto, mesmos as plantas estando em pleno florescimento aos 177DAT estas mantiveram intenso aumento na massa seca até a última coleta (215 DAT) (Tabela 1 e Figura 1).

A distribuição da massa seca variou bastante em função do órgão da planta. $O$ sistema radicular apresentou a maior proporção da massa seca total final, com $56,8 \%$ do total acumulado, seguido pela inflorescência $(31,6 \%)$ e parte aérea (11,6\%) (Figuras 1 e 2). O elevado acúmulo de massa seca no sistema radicular deve-se a característica da espécie em apresentar um sistema radicular pivotante extremamente agressivo. A estabilização do acúmulo de massa seca no sistema radicular se deu somente após os 170 DAT, isso é atribuído a maior translocação dos fotoassimilados para a inflorescência, uma vez que este foi o único órgão da planta que apresentou incremento significativo após os 170 DAT (Figuras 1 e 2). 
Figura 2. Distribuição da matéria seca acumulada nas diferentes partes das plantas de Rumex obtusifolius, ao longo do seu ciclo de desenvolvimento. Curitibanos, SC, 2017.

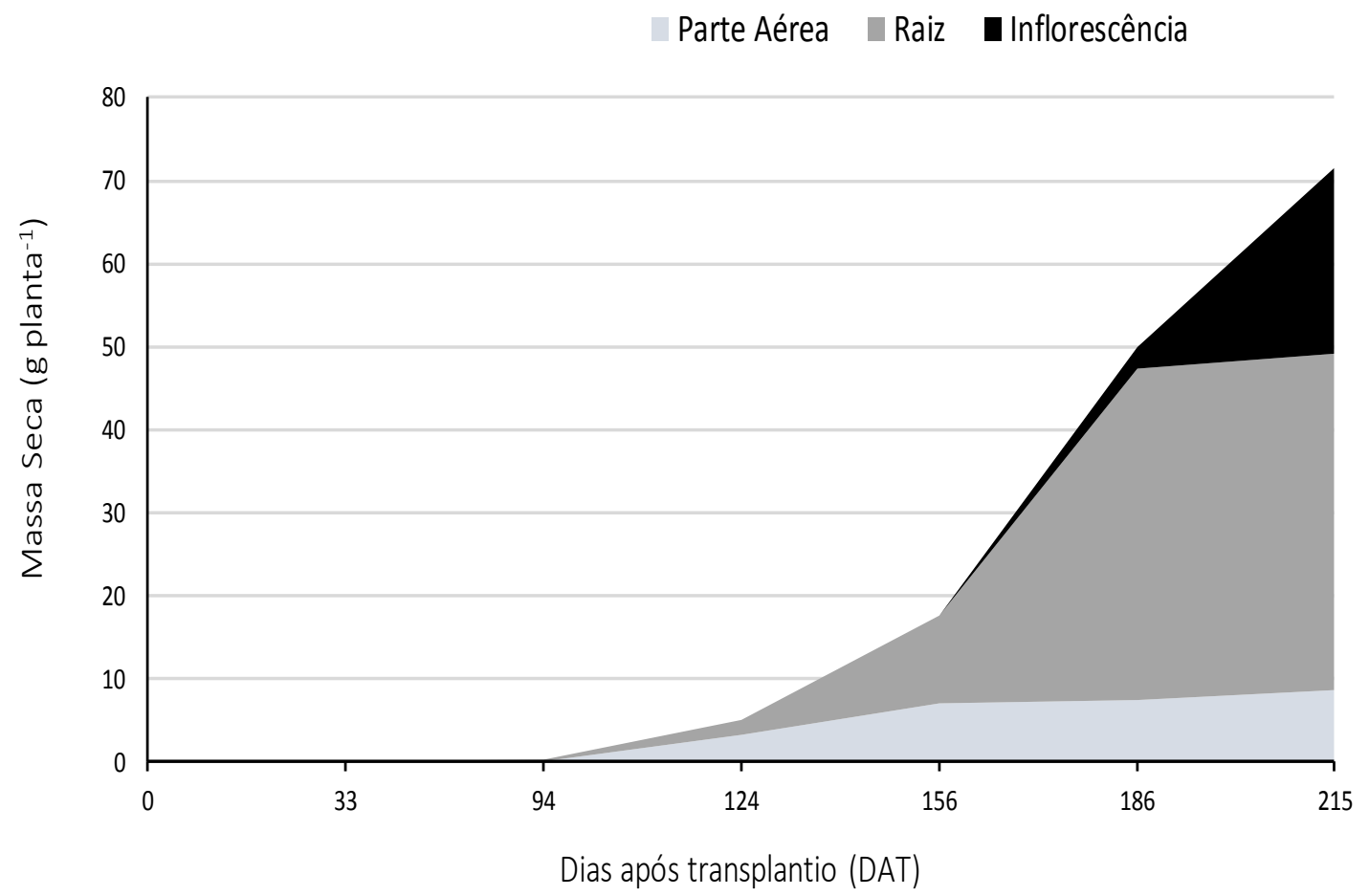

Segundo Carvalho et al. (2005) o maior desenvolvimento do sistema radicular com posterior formação da parte aérea favorece a dominação do espaço em que a planta está se desenvolvendo, principalmente em função da maior taxa de absorção de água e nutrientes.

O grande acúmulo de massa seca no sistema radicular é um problema, pois pode resultar em fonte de novas plantas. Isso foi confirmado através do rápido rebrote das plantas após o corte da parte aérea remanescente, onde um período de 10 dias foi suficiente para que $50 \%+1$ das plantas estivessem rebrotadas (Tabela 1). Segundo Alshallash (2018) não só a raiz inteira tem possibilidade de rebrote, segundo esse autor cerca de $70 \%$ dos fragmentos de raízes de $R$. obtusifolius também apresentam essa capacidade. Pye et al. (2011) também verificaram que a fragmentação da raiz principal da espécie Rumex crispus estimula o rebrote da planta. Isso confirma que a fragmentação das raízes não é a melhor prática de controle do rebrote de $R$. obtusifolius em condições de campo, desta forma a aração ou gradagem do solo acabariam aumentando a população de língua-de-vaca na área de cultivo, principalmente quando realizada em uma época com maior precipitação (PYE et al, 2011; ALSHALLASH, 2018). O mesmo vale para o uso de herbicidas com baixa translocação em aplicação única, pois irão controlar a parte aérea, contudo o sistema radicular rebrotará, regenerando a parte aérea e não alcançando controle satisfatório (ALSHALLASH, 2018).

Apesar do elevado acúmulo de massa seca no sistema radicular é importante salientar que nos primeiros 120 dias de ciclo da $R$. obtusifolia o crescimento e por sua vez a habilidade competitiva foram baixos, desta forma este seria o melhor momento para se entrar com medidas de controle, uma vez que o sistema radicular também está pouco desenvolvido minimizando a ocorrência de rebrote. Para Pye e Andrade (2009) as estratégias de controle de $R$. obtusifolius podem ser baseadas em uma tentativa inicial de prevenir ou retardar a emergência de plântulas, ou controlar no início de desenvolvimento, já que o crescimento é mais lento, essas estratégias permitirão que a cultura de interesse se desenvolva e escape da competição.

Segundo Baker (1974), uma das principais características que conferem o sucesso de uma planta daninha ao colonizar uma área agrícola é a capacidade da espécie em produzir e dispersar sementes durante todo o seu ciclo de vida. A emissão de inflorescência em $R$. obtusifolius deuse entre os 156 e 177 DAT sendo que $50 \%+1$ das plantas emitiram inflorescência com 172 DAT, e iniciaram a maturação dos frutos com 186 DAT (Tabela 1). 
O número médio de sementes produzidas por planta foi de 3.406 ( \pm 389) sementes. Segundo Carvers e Harper (1964) este número é bastante variável podendo ser de 100 a 60 mil por planta. Vale lembrar que as sementes não são a única forma de propagação de $R$. obstusifolius, já que a mesma também se propaga por meio de fragmentos do sistema radicular.

É importante destacar que estes resultados se referem a plantas de língua-de-vaca que se desenvolveram em ambiente não competitivo e em vasos, sendo que os resultados podem não ser exatamente os mesmos em condições de campo, uma vez que vários fatores podem afetar o desenvolvimento desta planta, como as características edafoclimáticas e a convivência com outras plantas, tanto da mesma espécie como de espécies diferentes, o que pode modificar as taxas de crescimento e desenvolvimento de língua-de-vaca.

\section{Conclusão}

A espécie $R$. obtusifolius apresenta crescimento lento até 120 DAT. A maior contribuição da massa seca total vem do sistema radicular e o número médio de sementes produzidas por planta foi de 3.406 ( \pm 389 ).

\section{REFERENCIAS}

ALSHALLASH, K.S. Emergence and root fragments regeneration of Rumex species. Annals of Agricultural Science, v.63, p.129-134, 2018. https://doi.org/10.1016/j.aoas.2018.08.001

BAKER, H. The evolution of weeds. Annual Review of Ecology System, v.5, n.1, p.1-24, 1974. https://doi.org/10.1146/annurev.es.05.110174.0 $\underline{00245}$

BENVENUTI, S.; MACCHIA, M.; MIELE, S. Light, temperature and burial depth effects on Rumex obtusifolius seed germination and emergence. Weed Research, v.41, n.2, p.177-86. 2001. https://doi.org/10.1046/j.1365-

$\underline{3180.2001 .00230 . x}$

BIANCO, S.; CARVALHO, L.B.; BIANCO, M.S.; YAMAUCHI, A.K.F. Crescimento e nutrição mineral de Urochloa arrecta. Planta Daninha, v.33, n.1, p.33-40, 2015. http://dx.doi.org/10.1590/S010083582015000100004.
BIANCO, S.; CARVALHO, L.B.; BIANCO, M.S. Crescimento e nutrição mineral de Sida rhombifolia, Planta Daninha, v.32, n.2, p.311317, 2014. http://dx.doi.org/10.1590/S010083582014000200008 .

CARVALHO, S.J.P.; MOREIRA, M.S.; NICOLAI, M.; LOPEZ-OVEJERO, R.F.; CHRISTOFFOLETI, P.J.; MEDEIROS, D. Crescimento e desenvolvimento da planta daninha capim-camalote, Bragantia, v.64, n.4, p.591-600, 2005. http://dx.doi.org/10.1590/S000687052005000400009

CARVALHO, S.J.P.; LOPEZ-OVEJERO, R.F.; CHRISTOFFOLETI, P.J. Crescimento e desenvolvimento de cinco espécies de plantas daninhas do gênero Amaranthus, Bragantia, v.67, n.2, p.317-326, 2008. http://dx.doi.org/10.1590/S0006$\underline{87052008000200007}$

CAVERS, P.B.; HARPER, J.L. Biological flora of the British Isles. Rumex obtusifolius L. and R. crispus L. Journal of Ecology, v.52, n.3, p.737-766, 1964. http://dx.doi.org/10.2307/2257859

HARSHAW, D.; NAHAR, L.; VADLA, B.; NASER, G.M.S.; SARKER, S.D. Bioactivity of Rumex obtusifolius (Polygonaceae). Archives Biological Science. v.62, n.2, p.387-92, 2010. http://dx.doi.org/10.2298/ABS1002387H

HESS, M.; BARRALIS, G.; BLEIHOLDER, H.; BUHR, L.; EGGERS,T.H.; HACK, H.; STAUSS, R. Use of the extended $\mathrm{BBCH}$ scale - general for the descriptions of the growth stages of mono- and dicotyledonous weed species. Weed Research, v.37, p.433-441, 1997. https://doi.org/10.1046/j.1365-3180.1997.d0170.x

LORENZI, H. Plantas daninhas do Brasil. 3. ed. Nova Odessa: Instituto Plantarum, 2000. 519p.

LORENZI, H. Manual de identificação e controle de plantas daninhas. 7. ed. Nova Odessa: Instituto Plantarum, 2014. 315p.

MOCCELLIN, R.; BELLÉ, C.; KASPARY, T.E.; GROTH, M.Z.; ROHRIG, B.; CUTTI, L.; CASAROTTO, G. Detection of Alternaria alternata causing leaf spot on Rumex obtusifolius in Southern Brazil. 
Plant Disease, v.102, n.8, p.1656, 2018. https://doi.org/10.1094/PDIS-12-17-2038-PDN

MOREIRA, H.J.C. Manual de identificação de plantas infestantes. São Paulo: FMC, 2011. 794p.

PATTERSON, D.T. Comparative ecophysiology of weeds and crops. In: DUKE S.O. (ed.). Weed physiology: reproduction and ecophysiology. Mississipi: CRC, 1984. p.103-127.

PYE, A.; ANDERSON, L. Time of emergence of Rumex crispus L. as affected by dispersal time, soil cover, and mechanical disturbance. Acta Agriculturae Scandinavica, Section B. v.59, n.6, p.500-505, 2009. https://doi.org/10.1080/09064710802400547

PYE, A.; ANDERSON, L.; FOGELFORDS, H. Intense fragmentation and deep burial reduce emergence of Rumex crispus. Acta Agricultutal Scandinavica,Section B., v.61, n.5, p.431-437, 2011. https://doi.org/10.1080/09064710.2010.5 $\underline{01764}$

ZALLER, J.G. Ecology and non-chemical control of Rumex crispus and R. obtusifolius (Polygonaceae): a review. Weed Research, v.44, n.6, p.414-432, 2004. https://doi.org/10.1111/j.1365-

$\underline{3180.2004 .00416 . x}$

ZALLER, J.G. Allelophatic effects of Rumex obtusifolius leaf extracts against ntive grassland species. Journal of Plant Diseases and Protection, p.463-470, 2006. 